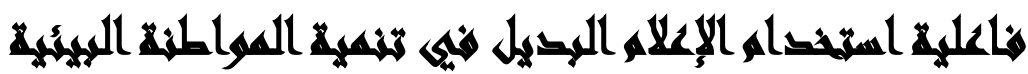

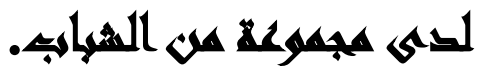

\section{[IV]}

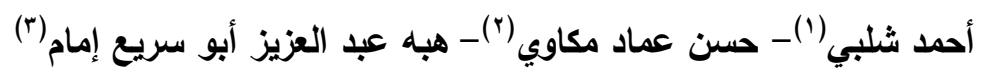

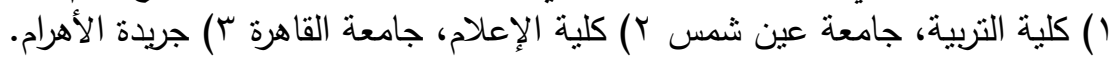

\section{المسرخلي}

يهدف البحث إلى تتمية المواطنة البيئية لدى مجموعة من الثباب المستخدمين لمواقع

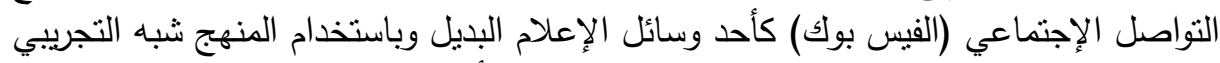

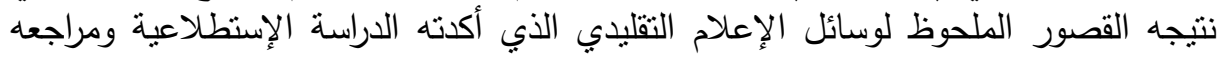

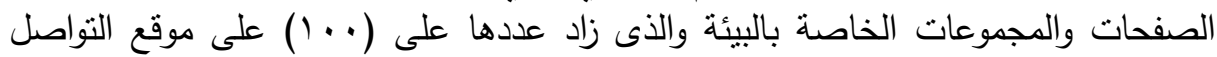

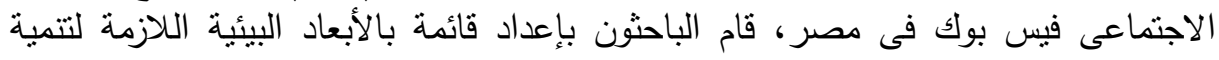

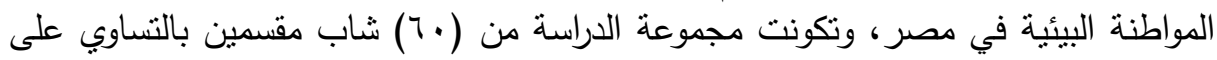
ثلاث مجموعات وهم المجموعة المستخدمة لصفحة الفئة الفيس بوكن، والمجموعة المستخدمة لمجموعة الفيس بوك، والمجموعة الضابطة.

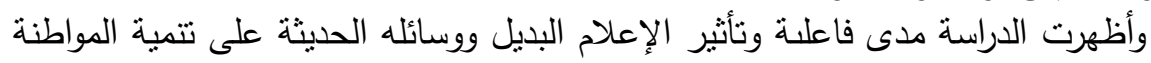

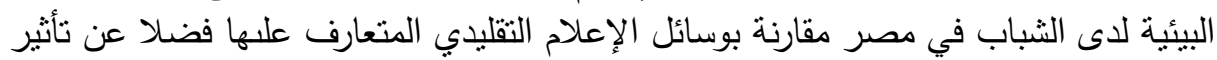

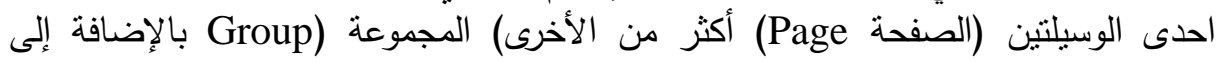

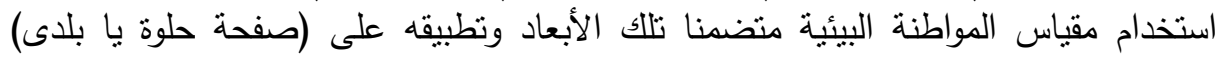

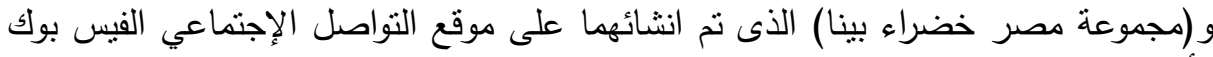
كأحد وسائل الإعلام البديل

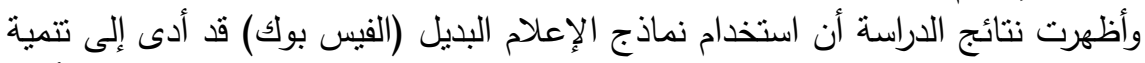

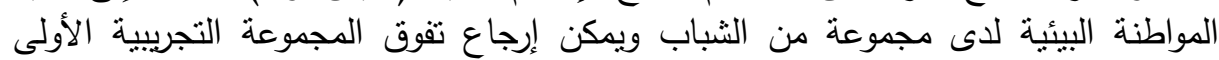

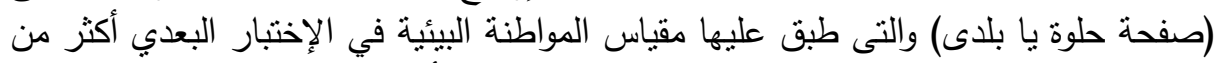

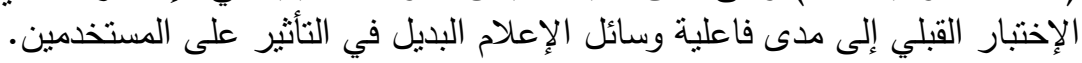

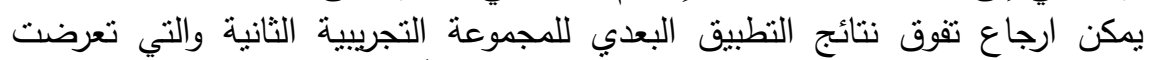

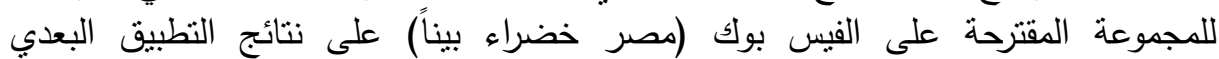

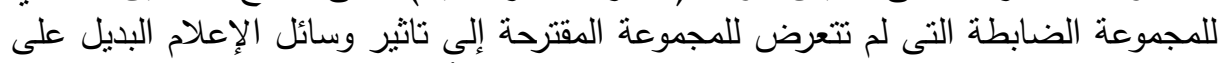

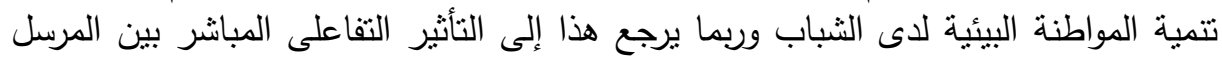

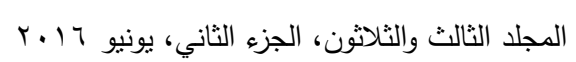


والمتلقي فضلاً عن وضوح الرسالة، وتهيئة البيئة الإتصالية المناسبة التى تحافظ على دائرية

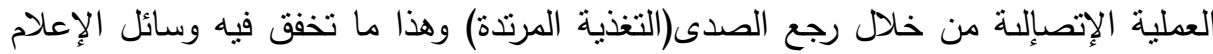

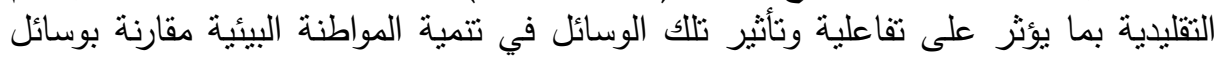
الإعلام البديل (التفاعلى).

ويوصي البحث بضرورة نطوير صفحات بيئية متخصصة البعائة على الفيس بوك من خلاد

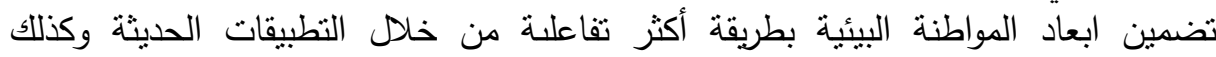

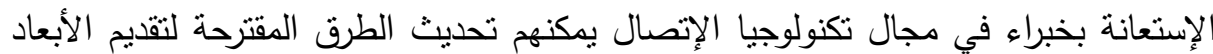

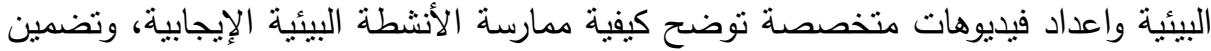

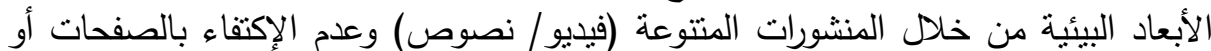
المجموعات المتخصصة لأنها أقل تأثنيراً.

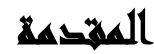

إن ما حققته ثورة الاتصالات من نجاح لم يسبق له مثيل بفضل النطور التقني المذهل

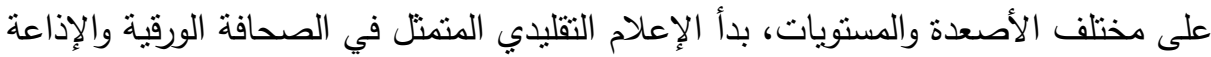
والتليفزيون وغيرهم يجابه العديد من المشكلات ويعاني كثير من السلبيات دفعت إلى ظهور مفهوم الإعلام البديل او ما يعرف بـ " الاعلام الثعبي" إلى دائرة الضوء ويتمنل في المواقع الالكترونية، المدونات، المنتديات، مواقع التواصل الاجتماعي (أولجا جودي سبيلي: 9 . . ب). بالإضافة إلى قيام أدوات الإعلام الجديدة بتغيير سيرورة العملية الاتصإلة برمنها عبر

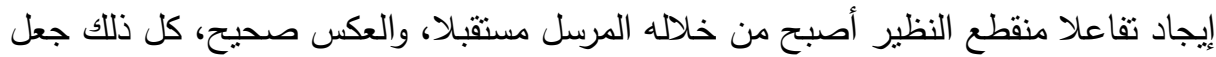

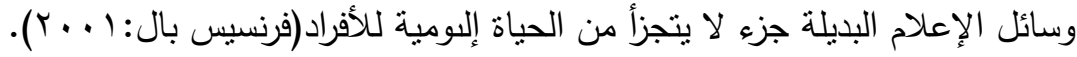
ومن هنا ظهرت الحاجة إلى تجريب واستخدام وسائل اعلام جديدة نتيجة قصور وسائل الاعلام التقليدية في حل المشكلات البيئية وخلق مواطن مسئول بيئياً. من خلال تتمية المواطنة البيئية وما لها من بعدا عالميا يعمقه الاهتمام بصحة الأرض فولإن وما علنها من هواء وماء وحجر وحيوانات وشجر وبشر ويدفع المواطن للمشاركة الفعالة والمسؤولة تجاه مجتمعه خاصة وكوكب الأرض عامة دون تأثز بالحدود الجغرافية،وذلك لرد كل التحديات البيئية التي تواجه أجيال الحاضر والمستقبل دون تمييز . 
فضلاً عن إكساب المواطنين المهارات والسلوكيات التي تسهم في الإصحاح البيئي وإعادة النوازن للنظام البيئي الطبيعي الذي أصابه الخلل، وتحسين السلوك البيئي المنبع في الإني الحياة العامة أثناء التعامل مع البيئة من خلال تصحيح المفاهيم البيئية السائدة لدى المواطنين وتعديل المعتقدات والأفكار البيئية الخاطئة، من أجل التتمية المستدامة .(دنيس روندينيلي،

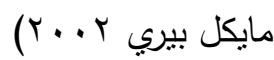
وهكذا يمكن القول ان المواطنة البيئية هي النتاج الحقيقي للوعي البيئي الناشئ اصلا من

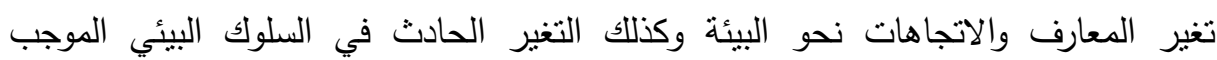

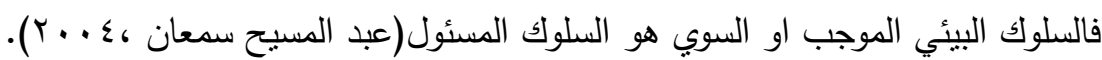

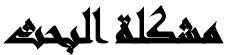

اتضح من خلال مراجعة أهم الصفحات والمجموعات المعنية بشئون البيئة على موقع التواصل الاجتماعى (الفيس بوك) والذى تجاوز عددهم (· ‥) صفحة ومجموعة منل (صفحة

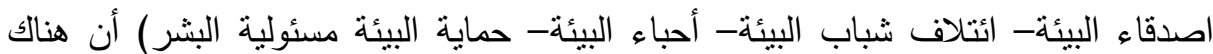
قصورا في معالجتها للمواطنة البيئية، كما أكدت الدراسة الاسنطلاعية التي نم إجرائها مع لئه مجموعة الثباب المستخدم (·r) شاب وبعض القائمين على وسائل الإتصال الخاصة بالإعلام البديل والتى أوضحت تاثثر موقع التواصل الاجتماعى (فيس بوك) على تتمية المواطنة لديهر حيث اعتبروه أولى وسائل الاعلام التى يحصلون منها على الاخبار واكثرها

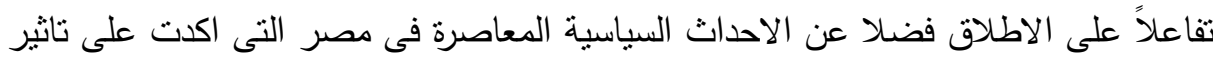

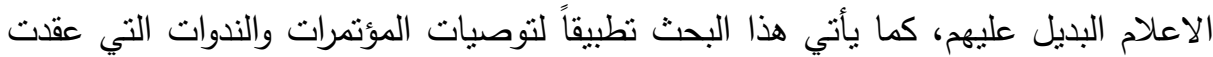
لدراسة البيئة بشكل عام والمواطنة البيئة بشكل خاص ومقترحات بعض الدراسات والبحوث

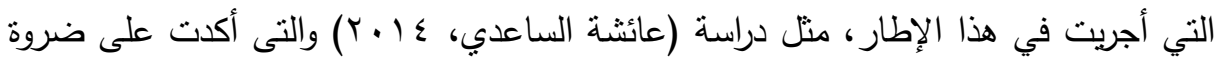
تتمية ابعاد المواطنة البيئية لاى الثباب فى المرحلة الجامعية، ودراسة (محسن العربي،

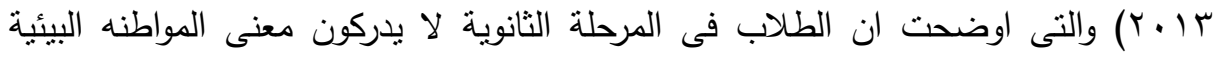
بابعادها المختلفة مما يستوجب اجراء العديد من البحوث التربوية التى تساعد على تتمية لتهن

$$
\text { المجلا الثالث والثلاثثو، الجزء الثاني، يونيو } 17 \text { ـ ب r }
$$


المواطنه لديهم، فضلا عن اهتمام مصر بالمواطنة البيئية وظهور وسائل حديثة للاعلام البديل فإن البحث الحالى يحاول الاستفادة من تللك الأساللب الحديثة للإعلام البديل (صفحة لإيه

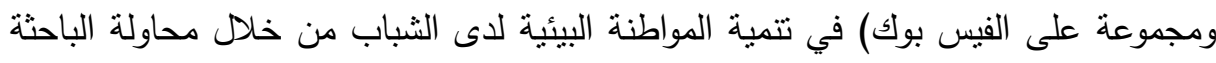
الإجابة عن التساؤل التإلى: ما فاعلية نموذج للإعلام البديل (الفيس بوك) على على تتمية المواطنة البيئية لاى مجموعة من الثباب؟ اعن البابه

\section{أسمكلا المهيث}

ما فاعلية نموذج للإعلام البديل (الفيس بوك) على تتمية المواطنة البيئية لدى مجموعة من الثباب؟ من السؤال الرئيسى الأسئلة التالية:

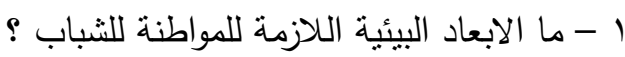
ץ- ما صورة صفحة (Page) على الفيس بوك تتضمن هذه الأبعاد؟ r- ما صورة مجموعة (Group) على الفيس بوك تنضمن نفس تلألك الإبعاد ؟

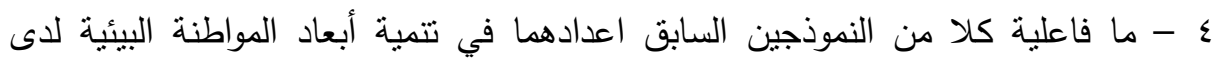
مجموعة من الثباب؟

\section{أهسا اهن المهيث}

يهدف هذا البحث إلى: تتمية المواطنة البيئية من خلال وسائل الإعلام البديل لدى مجموعة من الثباب.

\section{أهمبر الهمهA}

$$
\text { قد يستفاد من البحث الحالى فيما يلي: }
$$

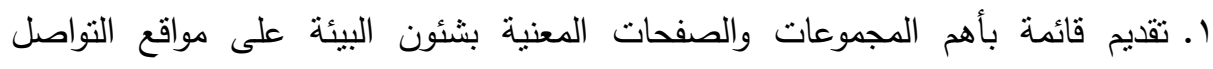
الإجتماعي يمكن الإستفادة بها من قبل مصمي المواقع الإلكترونية في وزارة البيئة وكذلك لكئل

$$
\text { الفضائيات وجهاز شئون البيئة. }
$$


r. تقديم وسائل حديثة من الإعلام البديل لتتمية المواطنة البيئية لاى الثباب بمكن الإستفادة منها في برامج التدريب الخاصة بمجالات التربية البيئية وتعلنم الكبار في وزارة التربية والتعليم.

r. تقديم مقياس للمواطنة البيئية يمكن أن يستقيد منه القائمون على الإتصال في وسائل الإعلام المختلفة وكذلك الباحثون في مجالات البيئة.

\section{منهمج الهيهمه}

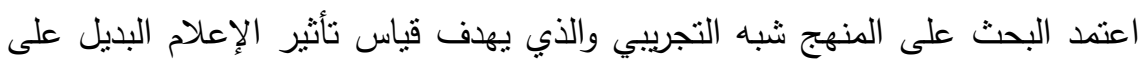
تتمية المواطنة البيئية لاى الثباب، حيث اعتمد الباحثون على التصميم التجريبي الثنائي للمجموعة التجريبية الواحدة (الاختبار القبلي، البعدي) والذي يهدف إلى قياس تأثير متغير لفئي مستقل على متغير تابع أو أكثر.

\section{هورت اللهمثي}

يقتصر البحث الحالى على الحدود التالية:

- اقتصرت عملية التجريب على ثلاث مجموعات من الثباب البالغين على موقع التواصل

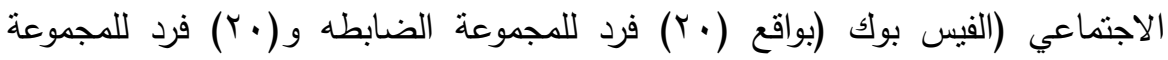

التجريبية الاولى (صفحة Page) و (·r) فرد للمجموعة الثانية (مجموعة (Yroup).

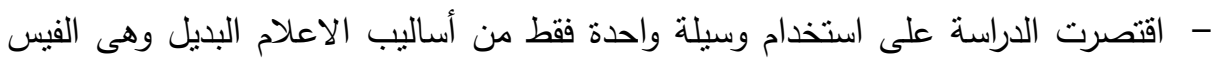
بوك. - اقتصرت الدراسة على استخدام نمطين من التفاعل (صفحة، مجموعة) على موقع الفيس بوك. 


\section{هزوضر المحمث}

ا. توجد فروق دالة إحصائيا بين متوسطي درجات المجموعة التجريبية الأولى (صفحة الفيس بوك) فى مقياس المواطنة في التطبيقين القبلي والبعدي لصالح التطبيق البعدي. r. توجد فروق دالة احصائياً بين منوسط درجات المجوعتين التجريبية الاولى والضابطة على مقياس المواطنة في التطبيق البعدي لصالح التجريبية الأولى. r. توجد فروق دالة احصائيا بين متوسطي درجات المجموعة التجريبية الثانية (مجموعة الفيس بوك) فى مقياس المواطنة في التطبيق القبلي والبعدي لصالح النطبيق. ع. توجد فروق دالة احصائيا بين متوسط درجات المجموعتين الثانية والضابطة على مقياس المواطنة في التطبيق البعدي لصالح التجريبية الثانية.

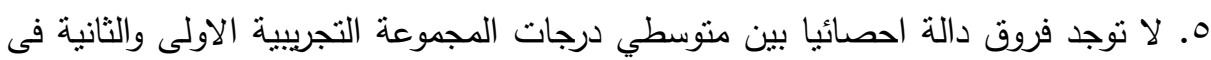
مقياس المواطنة في الاختبار البعدي للمقياس لصالح المجموعة التجريبية الأولى.

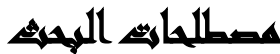

1 ـ الإعلام البايل: هو إعلام موازي لما هو رسمي، يميّزه بخاصيّة التكيّف مع مختلف

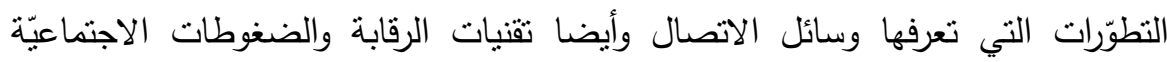
والسياسيّة، إضافة لقدرته على التشكّل إذ يظهر في أنشكال مختلفة حسب المرحلة التاريخيّة التي يمر بها المجتمع ونوعيّة مستعملي هذا الثكل الإعلامي. ومن أبرز تلك الأشكال (المواقع الالكترونية، الصحف الالكترونية، المدونات، مواقع التواصل الاجتماعي، الرسائل

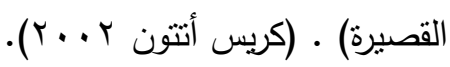

r ـ المواطنة البيئية: المواطنة البيئية تهدف إلى جعل المواطن واعيا باهم القضايا البيئية، وكذللك مسؤوليته وواجباته تجاه البيئة، لمواجهة التحديات التي نواجه اجيال الحاضر والمستقبل، المواطنة البيئية في مفهومها المتطور لا تعني أن يكون مواطن العصر مواطنا داخل وطنه فحسب، بل عضوا نشيطاوفاعلا في مجموعة بشرية اوسع،له واجبات تجاه شعوب تعيش خارج وطنه، وهذا ما يحمله مسؤوليات اكبر تجاه البيئة لتحقيق العدالة 
أحمد شلبي وآخرون

البيئية المرجوه من خلال اكساب المواطنين المهارات التي تساهم في الاصلاح البيئي من اجل التتمية المستدامة وتحسين السلوك البيئي المتبع في الحياة العامة. (ديفيد ميلباند

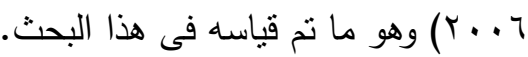

\section{الإطار اللنظلري}

مفهوم الإعلام البديل: تعددت المفاهيم التي تتاولت الإعلام البديل ومن أهمها: ـ يعرفه أولجا جودي سبيلي (Olga , 2010, 324)على أنه يوضع في مقابل الإعلام المسيطر حيث يعد مكوناً أساسياً في ترسيخ مفهوم المواطنة وقيم المجتمع المدني فضلا عن في فئل

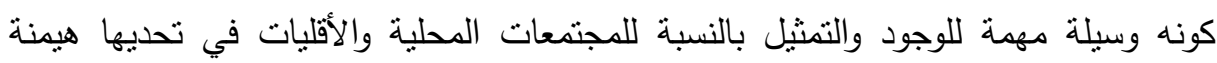
وسطوة الرقابة الثديدة المفروضة عليها من قبل الأنظمة الثمولية. ـ بينما عرفه بارتتيكو كاربنتز و آخرين 267 (Carpenter et , al , 2009 ) على أنه يتمنل فئل

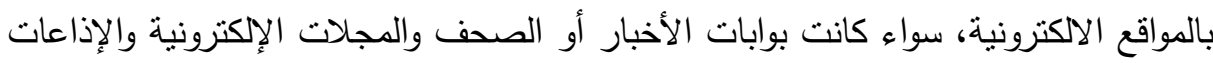

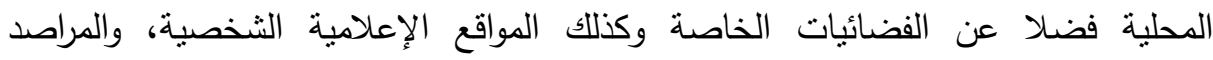
الإعلامية، والنشرات واللوائح البريدية، والمدونات، والمنتديات وغرف الدردشة التفاعلدة ذات التهات الوسائط المتعددة.

ويمكن للبحث الحالى تعريف الإعلام البديل على أنه: حالة التزاوج بين الكمبيوتر

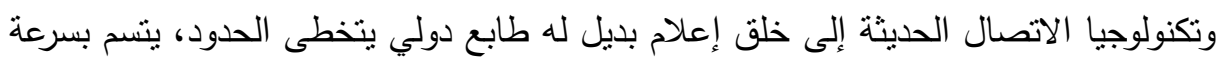
تغطية الأحداث ونقل الأخبار وكذلك سهولة التصفح والحصول على المعلومة والبحث عنها وهو إعلام مفتوح وحر إلى حدٍ كبير ويتسم بالاستقلالية ويتجاوز الرقابة ومضاد لها ويعمل من أجل إنهاء عصور القمع والاستبداد السياسي. وقد فتح هذا الإعلام نافذة كبيرة كانت موصدة لمناقثة المحظورات مثل الدين وحقوق الإنسان والمرأة، كما يعطي هذا الإعلام إمكانية

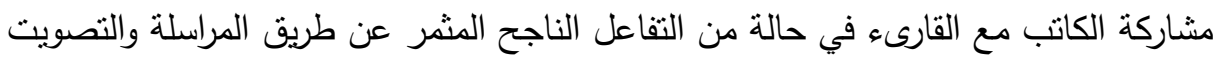

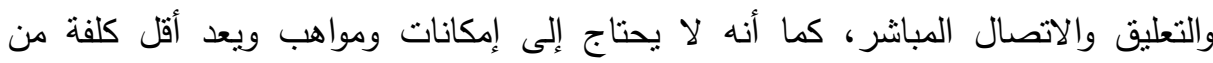
الإعلام التقليدي.

$$
\text { المجلا الثالث والثثلاثون، الجزء الثاني، يونيو } 17 \text { ـ ب r }
$$


خصائص الإعلام البديل: باستقراء الأدبيات المعنية بالإعلام البديل يمكن استخلاص j.stormer ، smiths 1998 , kamerits 2005 , olga 2010 (يصائصه كما يلي

(1) التفاعلية: تعني إزالة الفروق بين المرسل والمستقبل فتبادل المعلومات والأفكار سيتم في اتجاهين بصورة سريعة وفورية، أي أن المستخدم سوف يكون قادرا على التحكم في ليك المعلومات التي بريد الحصول عليها متى أرادها وبالثكل والمحتوى الذي بريده فالمستخدم يجب أن يقوم بعمل فاعل (active) يختار فيه المحتوى الذي يريد الحصول علنه وإرساله

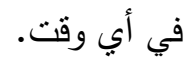

(r) تقليص سيطرة الجهات الرسمية: حيث يصبح بمقدور أي شخص لديه ارتباطات

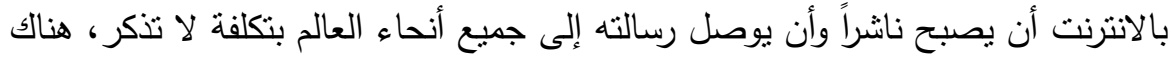
أيضا على الانترنت عشرات الآلاف من مجموعات الأخبار التي يمكن لمستخدميها مناقتشة

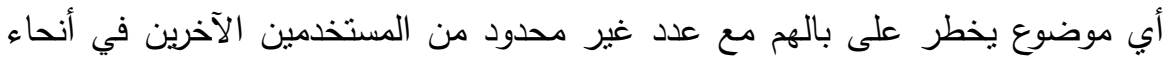

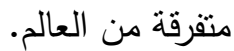

(ץ) متعدد الوسائط: هذا يعني أن المعلومات يتم عرضها في شكل مزيج من النص والصوت

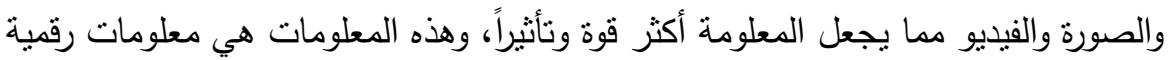
ينم اعدادعا وتخزينها وتعديلها ونقلها بشكل الكتروني. (ع) الاندماج: والتي كانت في الماضي وسائل مستقلة لا علاقة لكل منها بالآخر بشكل ألغيت معه تلك الحدود الفاصلة بين تلك الوسائل، فالصحف أصبحت صحف الكترونية بكل ما تحمله هذه الكلمة من معنى فهي تستخدم الاقمار الصناعية لإرسال صفحاتها إلى مدن حول العالم ومن ثم طباعتها، كما تستخدم الكمبيوتر في كافة عملياتها بل أنه يمكن

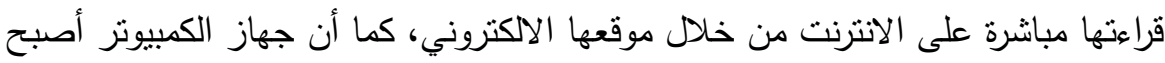
بالإمكان استخدامه كجهاز استقبال لبرامج التلفزيون والراديو وهكذا نجد أن جميع وسائل التهرئل الإعلام الجماهيرية الحالية أصبحت وسائل الكترونية بشكل أو بآخر . 
(0) السرعة: حيث بسمح بتداول حجم هائل ومنتوع من المعلومات والمضامين المعرفية

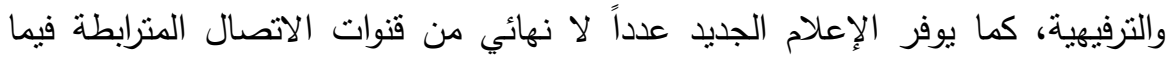
بينها، والتي تقلص تماماً من القيود الجغرافية والحدود السياسية، بالتإلى سنتضاعف الإدف أمام الجمهور فرص الاختيار الحر بين قنوات اتصالية عديدة، وبين عدد هائل من المضامين الإعلامية.

(T) قلة التكاليف: يتميز الإعلام الجديد بأنه رخيص جداً، ويتطور بفعل الثورات المتلاحقة في تكنولوجيا الاتصال والتي تؤدي إلى خفض منوإلى في أسعار الإعلام الجديد، وكلفة

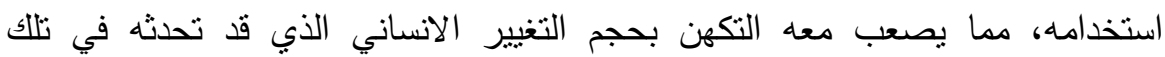

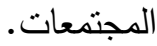

$$
\text { الإثكاليات التي تواجه الإعلام البديل: }
$$

(1) عدم القدرة على التحقق والوثوق من صحة ومصداقية العديد من البيانات والمعلومات

$$
\text { التي تحويها المواقع الالكترونية }
$$

(r) سهولة المساس بالقيم الدينية والاجتماعية للمجتمعات، وضعف السيطرة على نشر العنف

$$
\text { والنطرف والارهاب. }
$$

(r) وعدم التوازن في نوعية وحجم الرسائل الاعلامية الموجهة وبين استعداد المتلقي لها. (§) انتهاك الخصوصية وحقوق النشر والملكية الفكرية وارتكاب الجرائم الالكترونية.

(0) مشكلات الاتصال عبر الإنترنت، فلكل واقع افتراضى بنية تحتنة حقيقية من كابلات

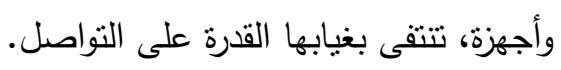

استراتيجيات لتقوية الإعلام البديل: ضرورة وجود بيئة مساعده ومواتية للإعلام البديل لبس فقط من منظور تتظيمي بحت بل أيضا على المستويات الإجتماعية والسياسية والثقافية وتعزيز أهمية التسليم بتتوع وسائل الإعلام البديل في دراسة السياسات الإعلامية والاتصإلية وكذا دورها في السياسة وفي الحياة اليومية وفي تقوية وتدعيم الديموقراطية من خلال مجموعتين من الإستراتيجيات: - اني 
- المجموعة الأولى: وتهدف إلى تقوية المواقع التي تتغلها وسائل الإعلام البديل والتي غالبا ما تحتل موقعا غير مستقر بين السوق والدولة. - ـ المجموعة الثانية: وتركز أكثر على السياق المتمعي التي تعمل فيه وسائل الإعلام البديل عن طريق توسيع الثبكة تستطيع وسائل الإعلام البديل أن تكون جزءا من حركة لهني

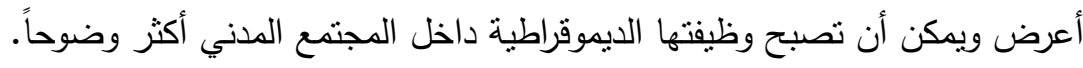
فضلا عن الحاجة لوجود تشريعات وقوانين عالإلة الجودة وتطبيقها في مختلف البلدان

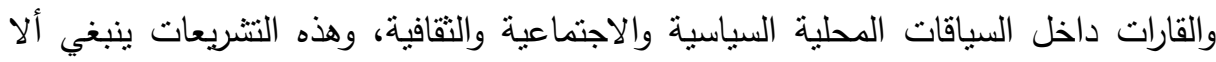
تقتصر على حماية حقوق الإنسان بل يجب أن تعترف بخصوصيات وفروق وسائل الإعلام

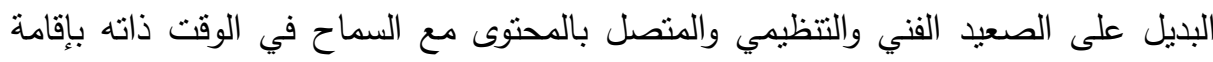
تحالفات إستراتيجية مع وسائل الإعلام العامة السائدة .

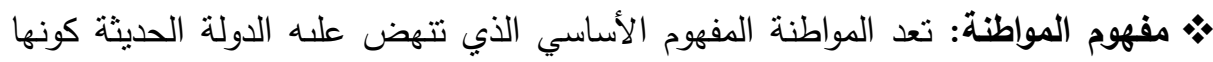

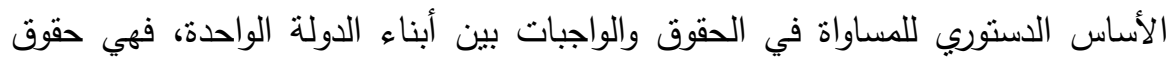
وواجبات وهي أيضا أداة لبناء مواطن قادر على العيش بسلام وتسامح مع غيره على لئ

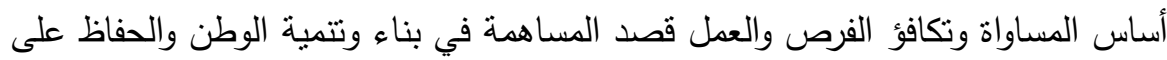
العيش المشترك فيه (Remy 1997).

\section{هـ مفوم المواطنة البيئية:}

ـ عرفها (وجيه بن قاسم القاسم بنى صعب:9 9. . . . . ص 9) على أنها: رسالة تتمنل في تطوير المواطن الحضاري ذي الثخصية المتوازنة، الذي يسهم بشكل فاعل في بناء هذا الوطن ويدافع عنه ويمارس حقوقه وواجباته التي كفلها له الدستور أو القانون.

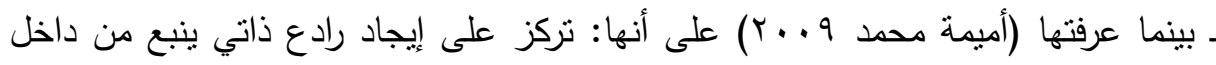
الإنسان، ويدفعه إلى حماية البيئة واحترامها، وهذا هو جوهر المواطنة البيئية.

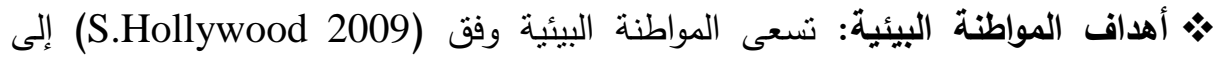
تحقيق ما يلي:

1. إكساب المواطنين المهارات التى نساهم فى الإصلاح البيئى من أجل التتمية المستدامة. 
r. تحسين السلوك البيئى اليومي. r. وقاية البيئة من المشاريع التتموية التى قد تلحق الضرر بالبيئة والمطالبة بإثبات عدم وجود أى ضرر على البيئة. عـ الإسهام فى رفع مستوى المعرفة والنقافة البيئية لعامة الناس وتحفيزهم على المشاركة فى لئه اتخاذ القرار ووضع الحلول للمشكلات البيئية. ه. تبادل الخبرات بين المنظمات الحكومية وغير الحكومية واللجنة الخاصة بالمواطنة فى برنامج الأمم المتحدة للبيئة (UNEP). مث مؤشرات المواطنة البيئية: تتمنل مؤشرات المواطنة البيئية في عناصر التربية البيئية التي تستهدف بناء وتتمية العناصر التالية:

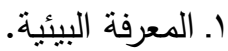

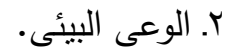
r. التتور البيئى. (البي.

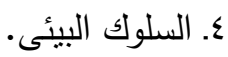
() م. الإدراك البيئى (Kaplan, 2005 •• أسس بناء المواطنة البيئية: تتمثل أسس بناء المواطنة البيئية من خلال تحديد الأهداف

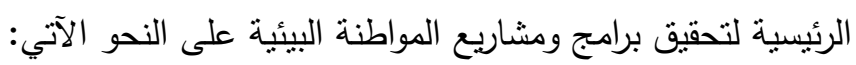

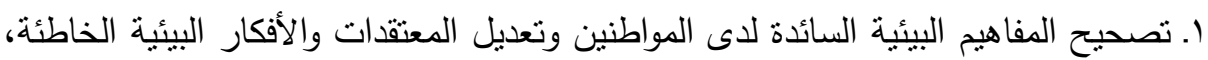

ومعالجة أسس المشاكل للسلوكيات السلبية الناجمة عن غياب مفهوم المواطنة البيئية. r. إكساب المواطنين المهارات والإلدات السليمة والمفيدة والصحيحة التي تساهم في المحافظة والإصلاح البيئي من أجل التتمية المستدامة. r. تحسين السلوك البيئي المتبع في الحياة العامة أثناء التعامل مع البيئة. ع. السعي إلى تجنب الأضرار البيئية قبل نشوئها والمطالبة بإثبات عدم وجود أضرار بعيدة المدى للأنشطة البيئية المقترحة. 
ه. الإسهام في رفع مستوى المعرفة والثقافة البيئية العامة للأفراد لتحفيزهم على المشاركة في اتخاذ القرارات ووضع الحلول المعنية بالثؤون البيئية والتنموية. T. تبادل الخبرات بين المنظمات الحكومية وغير الحكومية وبين اللجنة الخاصة ببرنامج

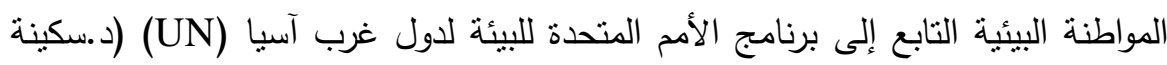

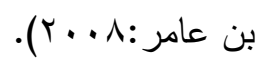

\section{خ العوامل المساعدة على تحقيق المواطنة البيئية:} ا. تفعيل القضايا البيئية الأولوية ضمن خطط التهيق التمية في الدولة واهتمام المسئولين. r. تعزيز التشريعات البيئية التي بستتد إلبها المواطنون في تحقيق المواطنة البيئية. rـ تعزيز الوعي البيئى من خلال برامج متخصصة من قِبل الجهات المعنية. ع. دعم الجمعيات البيئية الأهلية وزيادة عددها ومشاركتها في رسم الخطط والسياسات البيئية وتتفيذها.

هـ إعطاء القضايا البيئية الأهمية الكافية ضمن أنظمة التعلبم المختلفة وتتسيق جهودها. T. نوظيف وتتسيق جهود الجمعيات البيئية والاستفادة من المنظمات الدولية في دعم هذه الهنه الجمعيات.

V. التعاون مع المنظمات الثعبية وتحقيق التكامل فيما بينها نظراً لدورها الكبير في العمل 1. التأكيد على إنراك جميع الجهات المعنية في وضع السياسات والاستراتيجيات والخطط

$$
\text { وبرامج العمل البيئية.(إياد خليل:9 ج . . ب). }
$$




\section{إلجراءايت الهمشي}

للإجابة على تساؤلات البحث والتأكد من مدى صحة الفروض، قام الباحثون بالإجراءات

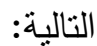

أولاً: إعداد قائمة بأبعاد المواطنة البيئية التى ينبغي تنميتها من خلال وسائل الإعلام البديل

كما يلي:

(1) مراجعة البحوث والدراسات السابقة العربية والأجنبية والوقوف على ما تم فى مجال

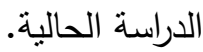

r) إعداد قائمة بأبعاد المواطنة البيئية التي ينبغي تتميتها من خلال وسائل الإعلام البديل لدى

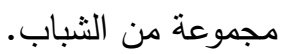

r) استطلاع رأي المتخصصين فى مجال البيئية فى هذه القائمة.

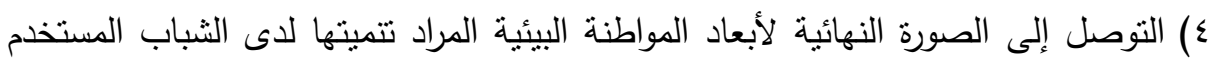

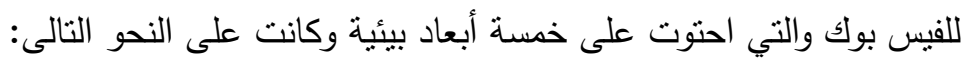

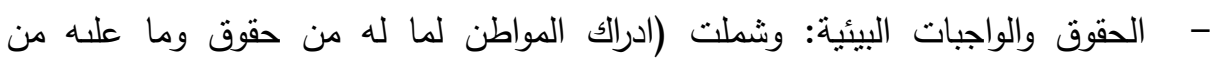

$$
\text { واجبات بيئية). }
$$

- القيم البيئية: وتضمت (1) (1) قيمة للحفاظ على البيئة.

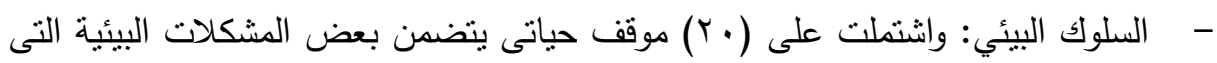

تهدف للكثف عن القدرة على التصرف الواعى والسليم تجاه البيئة والذى ينم عن

الاحساس بالمسئولية نحوها والمحافظه علنها وصيانتها.

ـ العدالة البيئية: واشتنلت على (T r) بعدا فرعيا وفقا للاستخدام الامنل لمكونات البيئة .

ثانيا: إعداد الصفحة والمجموعة المقترحة على الفيس بوك: والك

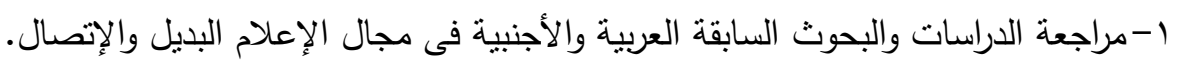

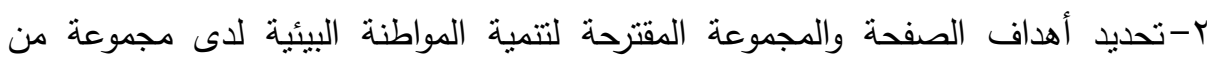
الثباب المستخدم للفيس بوك. 
r-حصر أكبر عدد من النماذج المثابهة للصفحات والمجموعات المهتمة بالبيئة على مواقع التواصل الإجتماعي. ع- انشاء صفحة (حلوة يا بلدي) على الفيس بوك تحنوى على مجموعة من الأهداف التى تتتاول الأبعاد الاساسية للمواطنة البيئية.

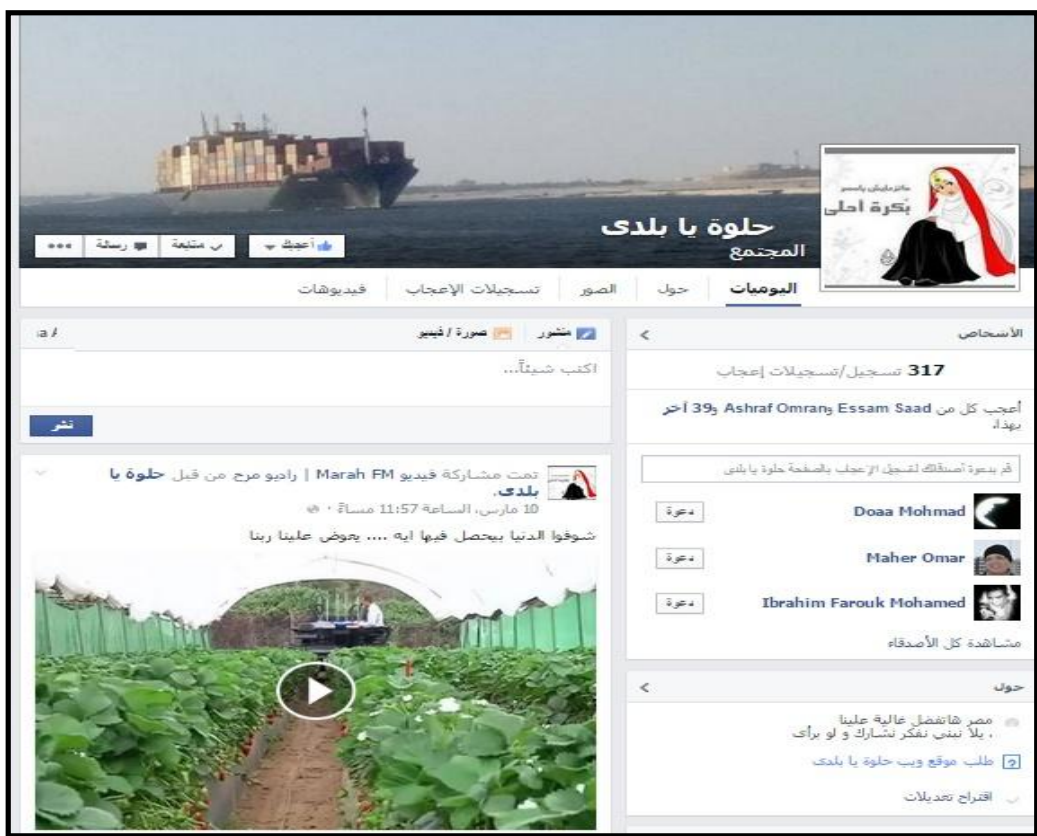

$$
\text { مجموعة مصر خضراء بينا على موقع الفيس بوك }
$$

ه- انشاء مجموعة (مصر خضراء بينا) على الفيس بوك تحتوي على مجموعة أهداف تتتاول

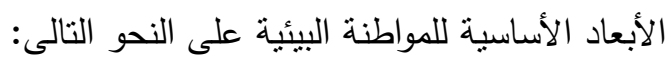
أ- تتمية المواطنة لدى مستخدمى الفيس بوك الاسئه ب- ادراك الشباب المستخدم لما لهم من واجبات وما علنهم من حقوه نحو البيئة ج- تتمية سلوكيات ايجابية تجاه البيئة من خلال فيديوهات تحفزهم للحفاظ على بيئة مصر جميله واخرى ترهبهم من النتائج الكارثية التى ستعود على البيئة من حولهم. 


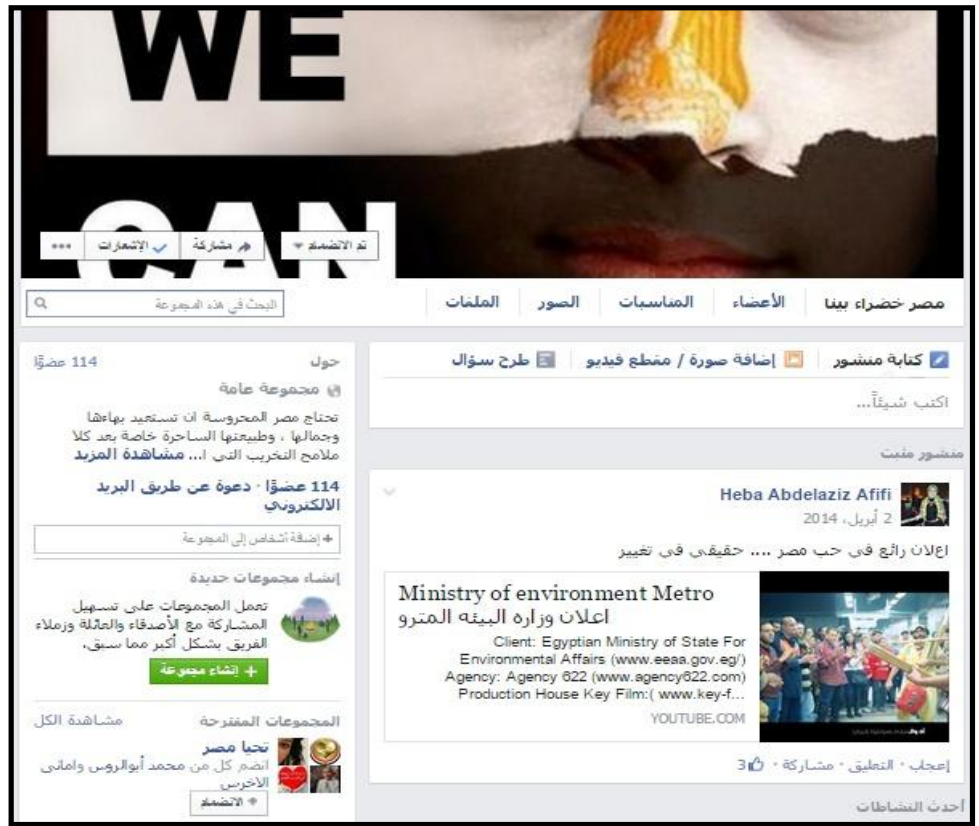

7-ضبط المحتوى الذى اشتمل على (الفيديوهات- النصوص- الصور) المعنية بمشكلات البيئة فى مصر من خلال عرضه على مجموعة من المحكمين فى مجالات الإعلام والتربية للتأكد من مناسبته.

V-ن نتاول القضايا حرق الأرز وتلوث الهواء، ومشكله البيئية المعاصرة مثل الطاقة وانقطاع الكهرباء، الكثافة السكانية المتزايدة والزحام، اهدار مياه النيل ومشكلة سد النهضة الثنة، وأفكار

$$
\text { جديدة لتدوير القمامة. }
$$

1-وضع الصفحة والمجموعة المقترحة فى صورتهما النهائية للتجريب. ثالثاً: إعداد أداة البحث وتثثمل: مقياس المواطنة البيئية لقياس المواطنة البيئية لدى الثباب واقتضى تحديد المواصفات الاولية للمقياس وصياغة مفردات المقياس، حيث بلغ عدد

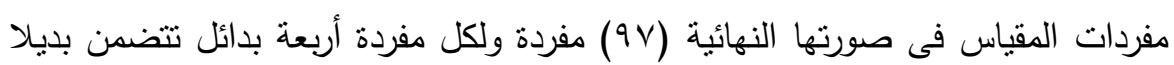
واحد اكثر صحه من الثلاثة بدائل الاخرى ويختار البالغين من مستخدمى الفيس بوك

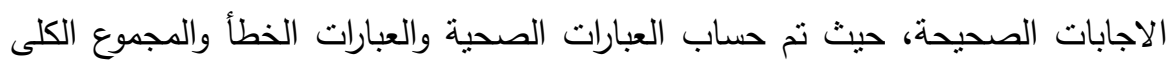


للمقياس، وقد تم اعطاء درجة للاجابة الصحيحة وصفرا للاجابة الخطأ وبالتإلى اصبحت

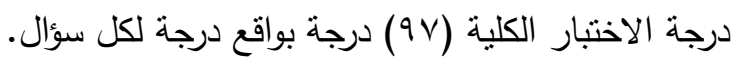

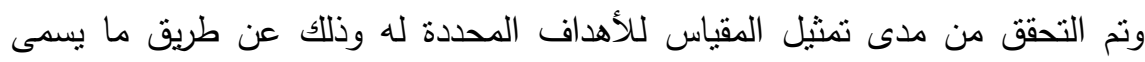
بصدق المحتوى وذلك بعرض المقياس فى صورته الاولية على عدد من من المحكمين المتخصصين فى مجال المناهج والتربية والاعلام بهدف الاسترشاد برأيهم وطلب الباحثون توضيح آرائهم فى:

- مدى وضوح الصياغة اللفظية لاسئلة المقياس ووضوحها علمياً.

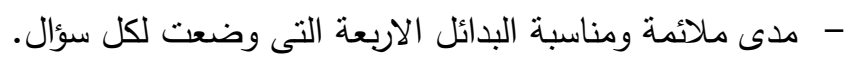
- مدى قدرة الاسئلة على قياس تتمية المواطنة البيئية لدى مستخدمى الفيس بوكن. - ابداء ايه اراء او مقترحات اخرى حول المقياس.

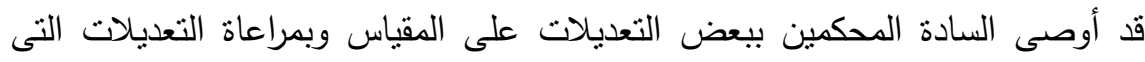

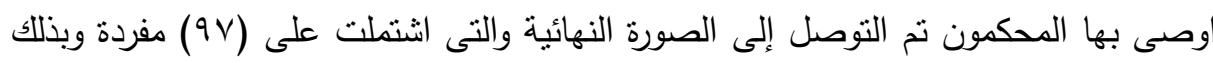
اصبح المقياس صادقا وصالحا للنطبيق لحساب ثباته. اثتنمل المقياس على الابعاد التالية: ـ بعد خاص بالحقوق والواجبات البيئية لدي الثباب يتكون من 10 سؤال.

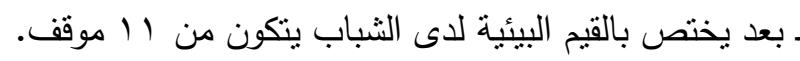

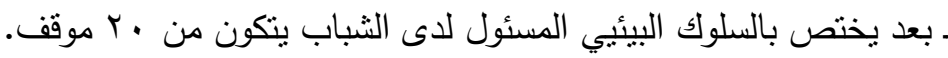
ـ بعد خاص بالعدالة البيئية يتكون من بـ بـ عبارة. لحساب ثبات المقياس قام الباحثون باستخدام معادلة كيودر وردتثاردسن (صلاح الدين علام، .... وبالفعل تم حساب ثبات وجد ان معامل الثبات طبقا لهذه المعادلة= VY, · وهذه القيمة عالإلة ويمكن الوثثوق بها. 
رابعاً: تجريب الصفحة والمجموعة المقترحة المقترح :تطبيق أدوات البحث قبلياً على عينه

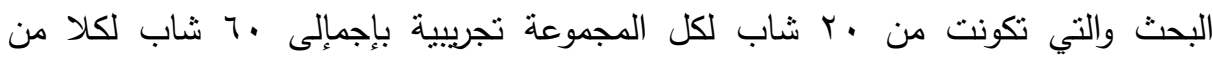

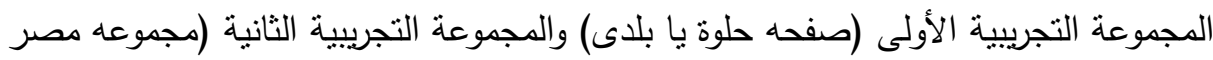

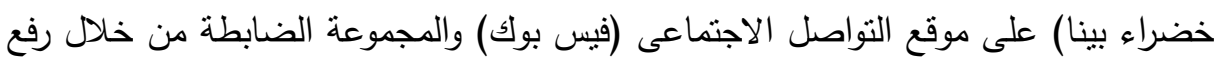
المقياس على الـ (gage و group) على موقع التواصل الاجتماعى (فيس بوك). جدول رقم(1) : نتيجة تفاعل الثباب على مجموعات البحث

\begin{tabular}{|c|c|c|c|}
\hline نتيجةٌ التفاعل & المجموعات & العدد & الفيس بوك \\
\hline$\% 00$ & التجربية الاولى & $\bar{r}_{\mathrm{r}}$ & الصفحة Page \\
\hline$\% \leqslant \wedge$ & التجريبية الثانية & $r$. & لمجموعة Group \\
\hline$\%$ \%. & الضابطة & $r$. & - \\
\hline
\end{tabular}

- تجريب الصفحة والمجموعة على مجموعة البحث على مدار سنه من فبراير ع ا بـ إلى الى فبراير 10 ـ r من خلال الفيس بوك.

- نطبيق أدوات البحث بعديا على مجموعة البحث.من خلال طرح مقياس المواطنة البيئية على كلا من الصفحة والمجموعة لقياس التفاعل.

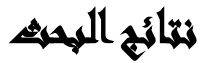

الفرض الأول: اختبار صحة الفرض الأول والذي نص على أنه "يوجد فروق دالة احصائيا فى مقياس المواطنة بين متوسطي درجات المجموعة التجريبية الأولى (صفحة الفيس بوك) في التطبيقين القبلي والبعدي لصالح البعدي". - ولإختبار صحة هذا الفرض تم حساب المتوسط الحسابي والإنحراف المعياري وقيمة (ت) لمعيد لثباب مجموعة البحث في النطبيق البعدي والقبلي لأبعاد المواطنة البيئية، ويوضح

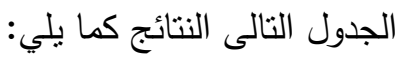


جلول رقم(ץ): نتائج صفحة مجموعة الفيس بوك

\begin{tabular}{|c|c|c|c|c|c|c|c|}
\hline \multirow{2}{*}{ الد الالةوي } & \multirow{2}{*}{ قَيمة } & \multicolumn{2}{|c|}{ التطبيق البعدي } & \multicolumn{2}{|c|}{ التطبيق القبلي } & \multirow[b]{2}{*}{ الارجة } & \multirow[b]{2}{*}{ البعد } \\
\hline & & $r_{\varepsilon}$ & $t^{5}$ & IE & ק & & \\
\hline داله & $10, V Y T$ & 1,100 & 91,10 & $\Lambda, 19 r$ & 0.01 & $9 \vee$ & أبعاد المواطنة \\
\hline
\end{tabular}

ويوضح الجدول السابق وجود فرق دال إحصائيا بين التطبيقين القبلي والبعدي لـقياس المواطنة البيئية على مجموعة من الثباب المستخدم للفيس بوك لصالح البعدى.

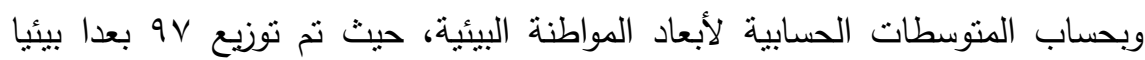
فرعيا لخمسة أبعاد بيئية رئيسية في المقياس، ومن خلال النتائج المبينة في الجدول تبين أنه يوجد فرق ذو دلالة احصائية للمجموعة التجريبية الأولى (صفحة حلوة يا بلدي) لصالح الحئ القياس

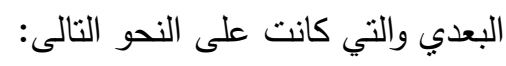
حيث كان منوسط البعدي (91,V0) أكبر من متوسط القبلي (1,0) الأثر (Av, ·) مما يدل على وجود أثراً كبيراً لصفحة الفيس بوك على تتمية المواطنة البيئية لاى الثباب وعليه فإن هذه النتيجة تدل على فاعلية الإعلام البديل في تتمية المواطنة البيئية، وعلده فقد تحقق الفرض الأول في البحث.

الفرض الثاني: وينص على أنه "يوجد فرق دال إحصائيا بين متوسطي درجات المجموعة

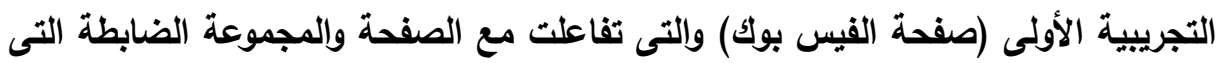
لا تستخدم الفيس بوك لصالح المجموعة التجريبية الأولى".

ولإختبار صحة هذا الفرض نم حساب المنوسط الحسابي والإنحراف المعياري وقيمة (ت) لثباب مجموعة البحث ولإختبار صحة هذا الفرض قام الباحث بحساب المتوسطات والإنحرافات المعيارية لدرجات أفراد العينة في مقياس المواطنة البيئية، وقد استخدم الباحث أسلوب تحليل التباين أحادي الاتجاه ويوضح ذلك كل من الجداول التالية: 
جدول رقم(ץ): مجموع الدرجات والمتوسطات الحسابية والانحرافات المعيارية لمجموعتي الدراسة في مقياس المواطنة البيئية

\begin{tabular}{|c|c|c|c|c|c|c|c|}
\hline الد الالة & قيمة & المعياري & متروسط & المعياري & الحسابي & العدد & المجموعة \\
\hline \multirow{2}{*}{ داله } & \multirow{2}{*}{$V r, r q$} & \multirow{2}{*}{$\cdot, 711$} & \multirow{2}{*}{$\varepsilon q, \mu$. } & $r, r r$ & $91, \vee 0$ & $r$. & الأولجىيبية \\
\hline & & & & $r, . r$ & $\leqslant r, \leqslant 0$ & $r$. & الضابطة \\
\hline
\end{tabular}

الفرض الثالث: والذي ينص على أنه "يوجد فرق دال احصائيا بين متوسطي درجات المجموعة التجريبية الثانية (مجموعة على الفيس بوك) فى مقياس المواطنة في التطبيق القبلي والبعدي لصالح البعدي".

ولاختبار صحة هذا لفرض تم استخدام اختبار (ت) وجاءت النتائج كما هو موضح

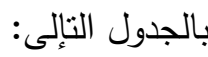

جدول رقم(؛): نتائج النطبيق القبلي/البعدي لمقياس المواطنة البيئية على مجموعة الفيس

\begin{tabular}{|c|c|c|c|c|c|c|c|}
\hline \multirow{2}{*}{ مستوى الدلالة } & \multirow{2}{*}{ قتيمة } & \multicolumn{2}{|c|}{ التطبيق البعدي } & \multicolumn{2}{|c|}{ التطبيت القبلي } & \multirow[b]{2}{*}{ الدرجة } & \multirow[b]{2}{*}{ البعد } \\
\hline & & $r_{\varepsilon}$ & $r_{P}$ & $1 \varepsilon$ & P & & \\
\hline داله & IT,VYT & $V, 174$ & $\wedge 7, \cdots$ & $9,1 \wedge r$ & $\varepsilon 1, \cdot v$ & & أبعاد المواطنة \\
\hline
\end{tabular}

حيث تم رصد درجات المستخدمين من الثباب- مجموعة البحث- في مقياس الأبعاد البيئية، وايجاد قيمة (t-test) لاختبار دلالة الفروق بين منوسط درجات الأفراد في التطبيق القبلي والبعدي لمقياس المواطنة.

وبحساب المتوسطات الحسابية لأبعاد المواطنة البيئية، نم توزيع و 9 بعدا بيئيا فرعيا

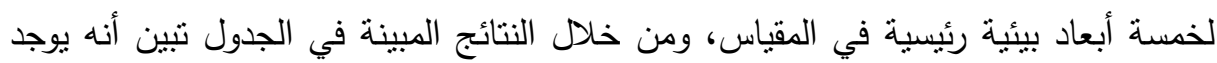
فرق ذو دلالة احصائية لأبعاد المواطنة البيئية لصالح القياس البعدي والتي كانت على النحو

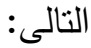




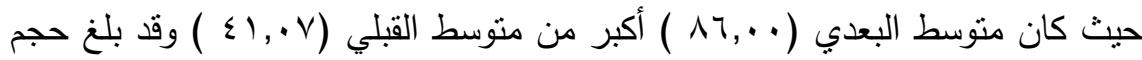

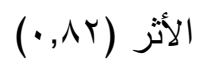

ـ حساب حجم التأثير والذي يدل على مدي تأثير المتغير المستقل ( الإعلام البديل وصفحة

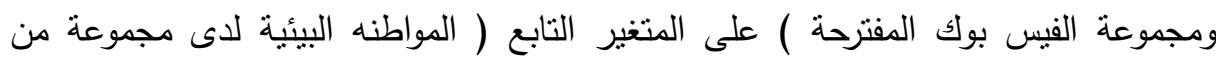
الثباب المستخدمين للفيس بوك ) وهو الدلالة العملية للنتائج، وذلك بإستخدام مربع( إينا ) تحديداً لمعرفة النسبة المئوية من تباين المتغير التابع الذي يمكن تفسيره بمعرفة المتغير المستقل، ويشير حجم التأثنر هنا إلى قوة العلاقة بين المتغيرين أو دليل الأثز الفعلى.

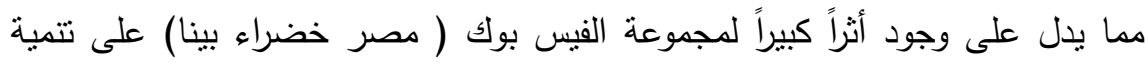
المواطنة البيئية لدى الثباب وعلنه فإن هذه النتيجة تدل على فاعلنة الإعلام البديل في تتمية المواطنة البيئية، وعلنه فقد تحقق الفرض الثالث في البحث. الفرض الرابع: ونص على أنه "يوجد فرق دال إحصائيا بين متوسط درجات المجموعتين الثانية (مجموعة مصر خضراء بيناعلى الفيس بوك) والضابطة على مقياس المواطنة في التطبيق البعدي لصالح التجريبية الثانية". ولإختبار صحة هذا الفرض قام الباحث بحساب المتوسطات والإنحرافات المعيارية لدرجات أفراد العينة في مقياس المواطنة البيئية، وقد استخدم الباحث أسلوب تحليل التباين أحادي الاتجاه ويوضح ذلك كل من الجداول التالية: جدول رقم(0): مجموع الدرجات والمتوسطات الحسابية والانحرافات المعيارية لمجموعتي الدراسة في مقياس المواطنة البيئية

\begin{tabular}{|c|c|c|c|c|c|c|c|}
\hline الدلالة & قيمة ت & المعياري & الفروقط & المعياري & الحستوسي & العدد & المجموعة \\
\hline \multirow{2}{*}{$\cdot, \cdot 1$} & \multirow[t]{2}{*}{$v \varepsilon, r q$} & \multirow{2}{*}{ •,Vדr } & \multirow{2}{*}{$\leqslant \wedge, 0}$. & $r, r \Sigma$ & $\wedge \neg, \cdots$ & $r$. & \\
\hline & & & & $T, \cdot T$ & $\leqslant Y, \leqslant 0$ & $r$. & الضابطة \\
\hline
\end{tabular}


ومن خلال الجدول التالية يتضح وجود فروق ذات دلالة احصائية بين المجموعات الثلاث التجريبية الضابطه والتجريبية الاولى (الصفحة) والتجريبية الثانية (المجموعة) ولهذا تم

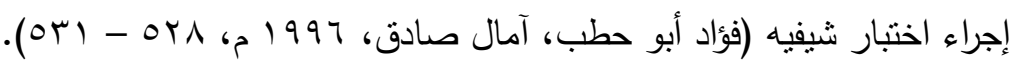

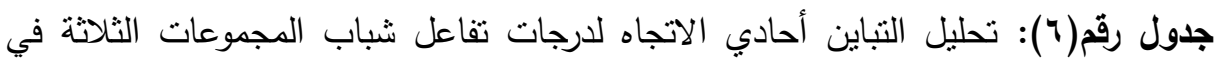
مقياس المواطنة البيئية

\begin{tabular}{|c|c|c|c|c|c|}
\hline الإحصائية & الفائية & المتوبعات & الحرباتة & المربعات & مصدر التباين \\
\hline \multirow{2}{*}{$\cdot, \cdot 1$} & \multirow{2}{*}{ אזT, 190 } & I & $r$ & $r q .7 V, V \ldots$ & بين المجموعات \\
\hline & & $V, \leq 01$ & or & $\varepsilon r \varepsilon, V,$. & داخل المحموعات \\
\hline & & & 09 & $r q \leq q r, \varepsilon \ldots$ & التباين الكلي \\
\hline
\end{tabular}

جدول رقم(V): مصدر الفروق بين المجموعات الثلاث ودلالتها وفق اختبار شيفيه.

\begin{tabular}{|c|c|c|c|}
\hline الدالالة الإحصائية & المتوسطات الحسابية & المجموعات & ? \\
\hline * & $91, \mathrm{VO}$ & التجريبية الأولى & 1 \\
\hline *** & $\begin{array}{l}\wedge \tau, \cdots \\
\leqslant Y, \leqslant 0\end{array}$ & التجريبية الثانية & r \\
\hline
\end{tabular}

يتضح من الجدول وجود فروق دالة احصائيا عند مستوى دلالة (1.,. •) بين منوسط

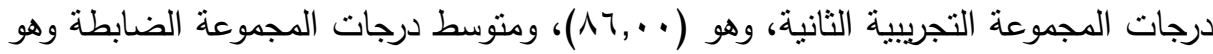

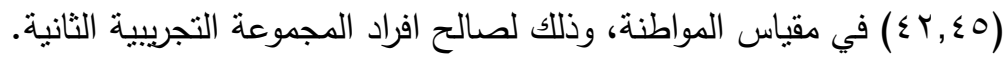
وهذه الفروق فروق جوهرية لا ترجع إلى الصدفة بين متوسطات درجات معدل الزيادة في

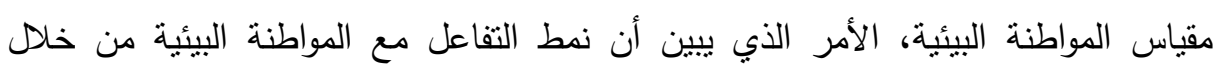
مجموعة الفيس بوك أكثر تأثيراً وتفاعلاً فضلاً عن أن تتمية المواطنة البيئية من خلال وسائل

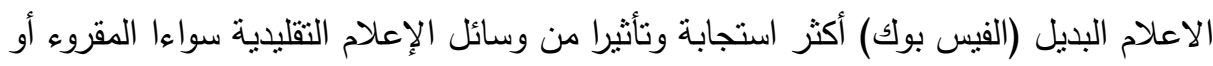
المرئي أو المسموع، لأنها تضيف عنصر التفاعل المباشر بين أطراف العملية الاتصالية، وعلى هذا نم قبول الفرض الرابع للاراسة. 
الفرض الخامس: قد نص على أنه" لا يوجد فرق بين متوسطي درجات المجموعة التجريبية الأولى والثانية في الإختبار البعدي لمقياس المواطنة البيئية".

ولإختبار صحة هذا الفرض تم حساب مجموع الدرجات، والمتوسطات الحسابية، والإنحرافات المعيارية لمجموعتي الدراسة، واستخدمت تحليل التباين احادي الإتجاه كما هو موضتح بالجدول: جدول رقم(^): مجموع الدرجات والمتوسطات الحسابية والانحرافات المعيارية لمجموعتي الدراسة في مقياس المواطنة البيئية

\begin{tabular}{|c|c|c|c|c|c|c|c|}
\hline الدلالةي & قيمة ت & المعباري & الفروق & المعياري & الحستوسي & العدد & المجموعة \\
\hline \multirow{2}{*}{$\cdot, \cdot 1$} & \multirow{2}{*}{$r_{0}, r_{q}$} & \multirow{2}{*}{$1, V \pi r$} & \multirow{2}{*}{$r \cdot, 0$. } & $r, r r$ & $91, \vee 0$ & $r$. & الأتجريبية \\
\hline & & & & $T, Y \Sigma$ & $\wedge \uparrow, \cdots$ & $r$. & الثانجيةيبية \\
\hline
\end{tabular}

ويتضح من الجدول أنه نوجد فروق ذات دلالة إحصائية عند مستوى دلالة (1 .,•) من

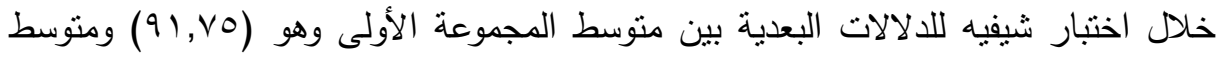
المجموعة الثانية وهو (., (^) في الإختبار البعدي لصالح المجموعة الأولى (صفحة حلوة

$$
\text { يا بلدي) على الفيس بوك. }
$$

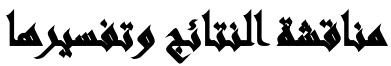

تظهر نتائج الدراسة أن استخدام نماذج الإعلام البديل (الفيس بوك) قد أدى إلى تتمية المواطنة البيئية لاى مجموعة من الثباب، ويتضح ذلك من خلال مناقتشة النتائج وتفسيرها

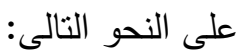
1- فيما يتعلق بصفحة على الفيس بوك (حلوة يا بلاي): يمكن إرجاع تفوق المجموعة

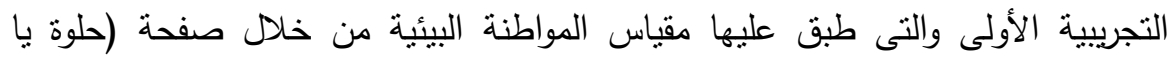
بلدي) على موقع التواصل الإجتماعي (الفيس بوك) في الإختبار البعدي أكثر من من من التئ 
الإختبار القبلي إلى مدى فاعلدة وسائل الإعلام البديل في التأثثر على المستخدمين وتتمية

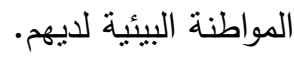

ويمكن ارجاع هذه النتيجة إلى عدة عوامل أهمها: - تقديم المعلومات البيئية بطريقة أكثر تفاعلية تترك أثرا واضحا للتعلم لدى الثباب. - احتواء الصفحة على اسئلة متتوعة ومتعددة تثير الحوار التفاعلى والنقاش بين المستخدمين وبعضهم البعض أو بينهم وبين "أدمن" الصفحة وهي الباحثة هنا مما كان له بالغ الأثر في تتمية المواطنة البيئية لدى المجموعة التجريبية الأولى. لبون. - احتواء الصفحة على مثيرات سمعية وبصرية ونصية مما يزيد من نسب التفاعل علهها من النه قبل المستخدمين وتأثرهم بالمعلومات البيئية المقدمة، وهو ما يتفق مع ما أوردته (هناء

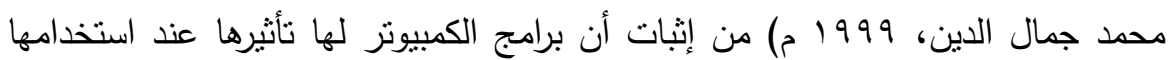
كوسيلة تعلنمية للشرح المخصوص في تتمية مهارات التفكير . يمكن إرجاع تفوق المجموعة التجريبية الأولى (صفحة الفيس بوك) في مقاتهات مقياس المواطنة البيئية على المجموعة الضابطة في التطبيق البعدي إلى التأثير الكبير لوسائل الإعلام البديل

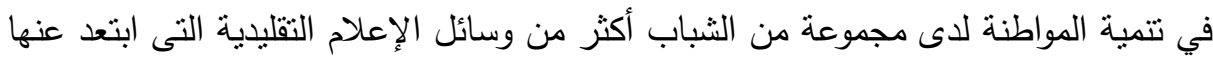
الجمهور مؤخرا وربما يرجع هذا لعدة أسباب من أهمها:

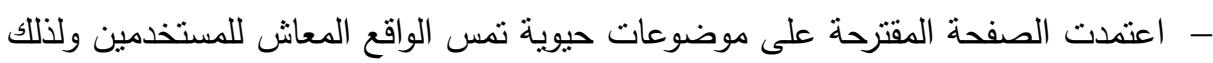

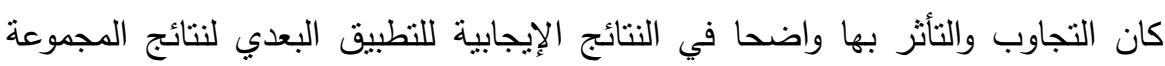

$$
\text { التجريبية الأولى التى تعرضت للصفحة المقترحة. }
$$

- الخطوات المستخدمة أثناء التفاعل على الصفحة، ساهمت في نتمية المواطنة البيئية وهو

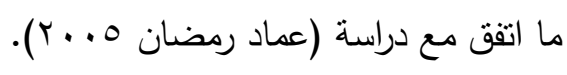

r- فيما يتعلق بمجموعة على القيس بوك (مصر خضراء بينا): يمكن ارجاع تفوق التطبيق

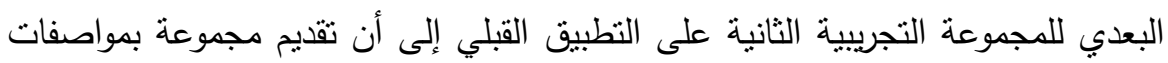

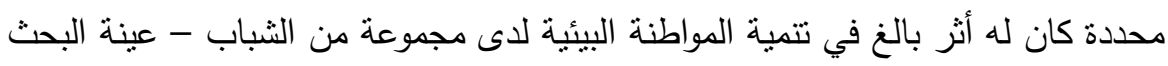


- نتيجة لإستخدام الوسائل الإتصالية الحديثة وما تقدمه من تكنولوجيا تؤثر على التفاعل

بين المرسل والمستقبل بشكل ايجابي، ويمكن ارجاع ذلك للأسباب التالية: - الإختبار الدقيق للمواد البيئية التى تم عرضها على أعضاء المجموعة أثرت بدرجة كبيرة

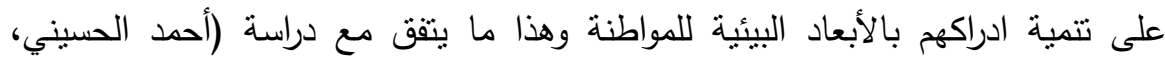

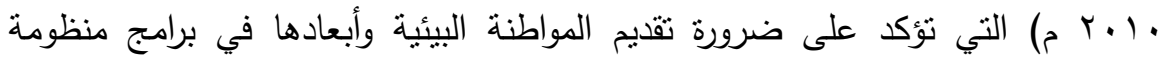
الإعلام المدرسي وأهمية تضمينها في شتى المناهج بشكل يساعد على تتمية المواطنة. - التفاعل التعاوني بين أفراد المجموعة كان له تأثيراً واضحاً في تتمية المواطنة البيئية

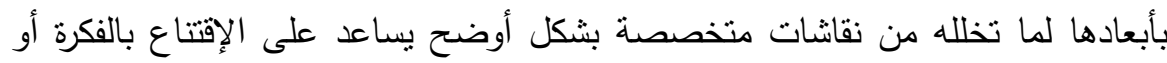

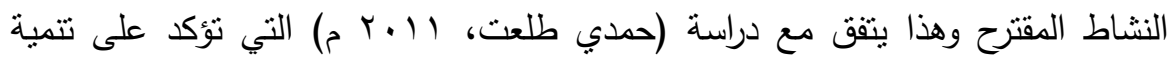

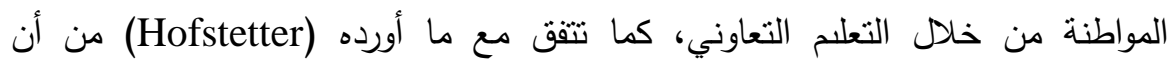
استخدام الكومبيوتز لعرض مزيج من الصوت والصورة بطريقة متصلة ومترابطة يتيح للمستخدم التتقل بينها والتفاعل معها والابتكار . - يمكن ارجاع تفوق نتائج التطبيق البعدي للمجموعة التجريبية الثانية والتي تعرضت للمجموعة المقترحة على الفيس بوك (مصر خضراء بينا) على نتائج التطبيق البعدي لني للمجموعة الضابطة التى لم تتعرض للمجموعة المقترحة إلى تأثير وسائل الإعلام البديل

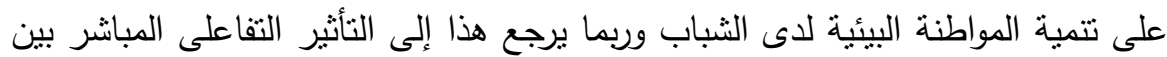

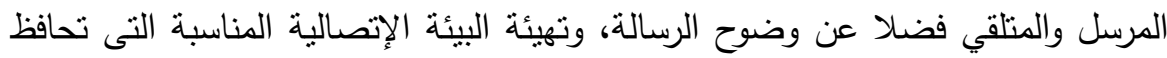

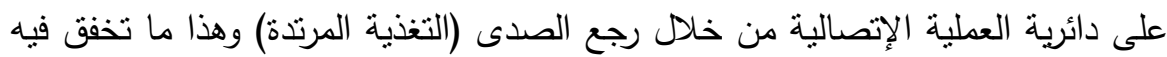

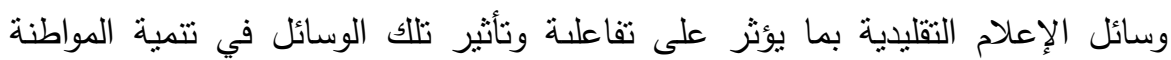
البيئية مقارنة بوسائل الإعلام البديل (التفاعلى).

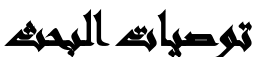

ا ـ نطوير صفحات بيئية متخصصة على الفيس بوك من خلال تضمين أبعاد المواطنة البيئية بطريقة أكثر تفاعلية من خلال النطبيقات الحديثة. 
r. الإستعانة بخبراء في مجال تكنولوجيا الاتصال يمكنهم تحديث الطرق المقترحة لنقديم الأبعاد البيئية واعداد فيديوهات متخصصة نوضيراء فيجح كيفية ممارسة الأنشطة البيئية الإيجابية. r. تضمين الأبعاد البيئية من خلال المنشورات المتتوعة (فيديو/ نصوص) وعدم الإكتفاء بالصفحات أو المجموعات المتخصصة لأنها أقل نأثيراً.

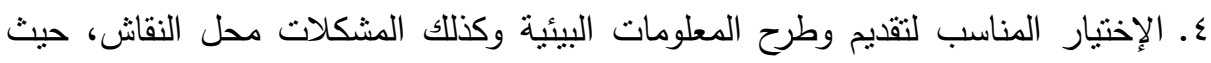
وجدت الباحثة من خلال الملاحظة المباشرة عزوف المستخدمين عن أية تفاعلات بعيدة عن الأحداث السياسية أو الفنية أو الرياضية الكبرى.

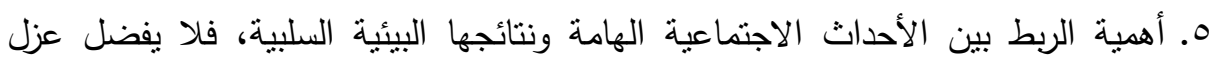
القضايا البيئية عن الواقع الفعلى المعاش.

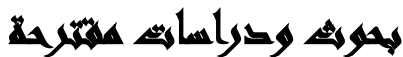

فى ضوء إجراءات ونتائج البحث الحالى يقترح إجراءات دراسات وبحوث فى المجالات

1- بحوث مماثلة للبحث الحالى تتتاول وسائل مختلفة للإعلام البديل مثل (تويتر Twiter-

انستجرام Instgram وقياس أنثرها في تتمية المواطنة البيئية. r- دراسة للتعرف على دور وسائل الإعلام فى تحقيق متطلبات العدالة البيئية لاى الفئات

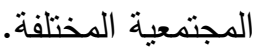

\section{المراليع}

أولجا جودي سبيلي، بارت كاميرنس، نيكو كاربنتيير، فهم الإعلام البديل-نرجمة علا أحمد

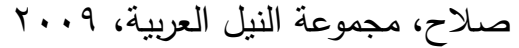

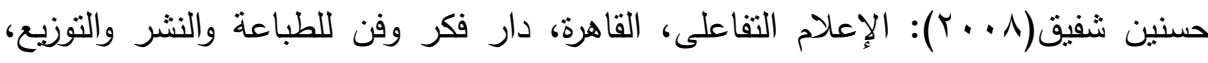

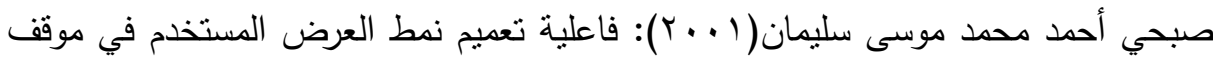

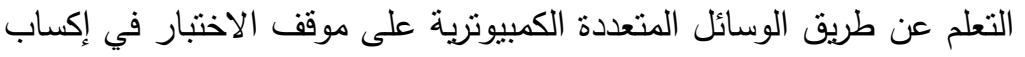




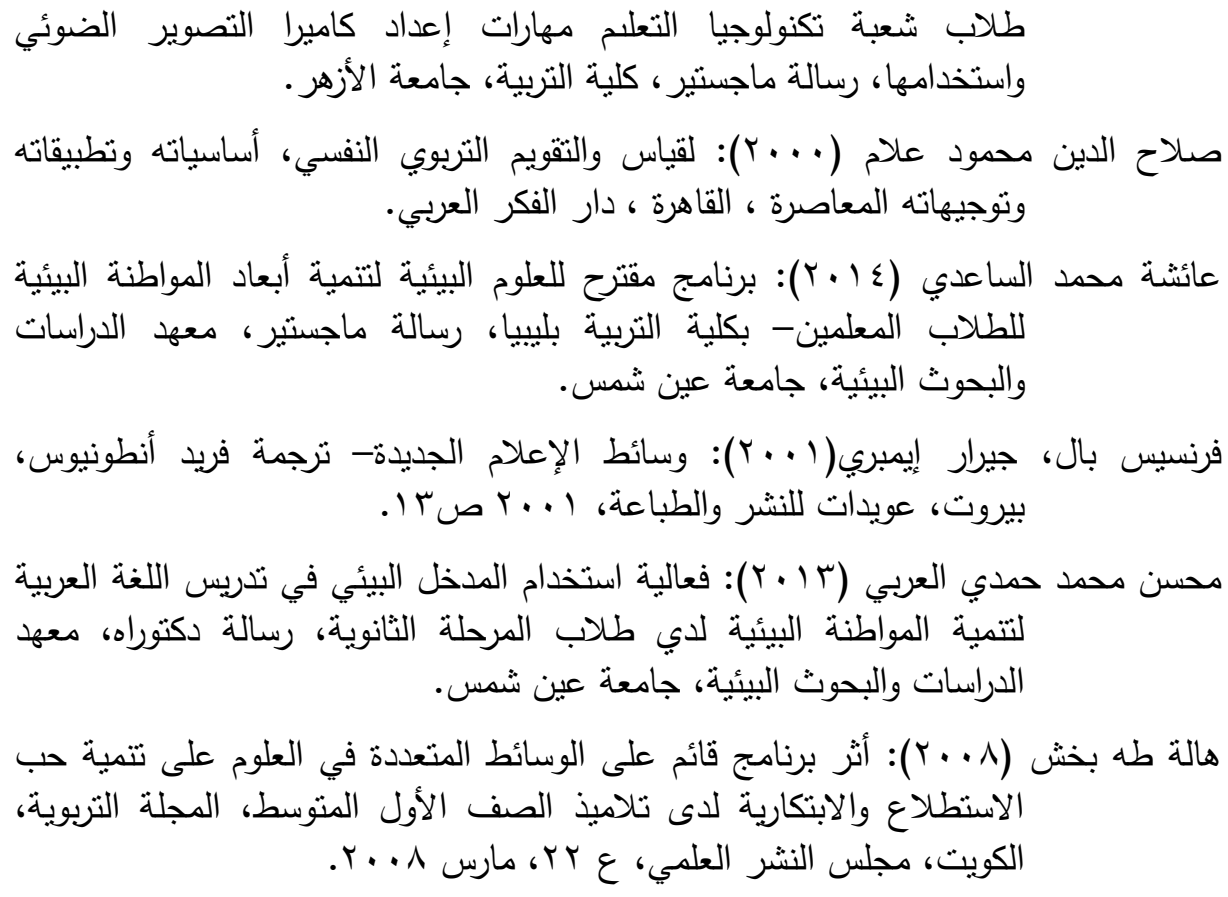

Ebreo, A., Hershay, J., \& Vining, J. (1999): "Reducing Solid Waste Linking Recycling to Environmentally Responsible Consumerism", Environment and Behavior, Vol. 31, No. 1, p 474-479.

http://eprints.usm.my/9542/1/the_effects_of_a_multimedia_constructivi st environment_on_students\%e2\%80\%99_achievement_and_ motivation.pdf

Kaplan, S. (2000): "Human Nature and Environmentally Responsible Behavior", Journal of Social Issues, Vol. 56, No. 3, p 491508 .

Simon hailwoodEnvironmental Citizenship as Reasonable Citizenship , Routledge, Liverpool, UK 2005 


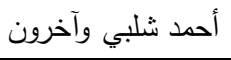

Vickneasvari A/P Krishnasamy (2007): The effect of multimedia constructive environment on students achievement and motivation in the learning of chemical formula and equations . available on line at

W,Hsin-Kai , Krajcik ,Jseph S., Soloway, Elliot (2009): promoting conceptual understanding of chemical representations: students, use of a visualization tool in the classroom. Eric ed 443

\title{
THE EFFICACY OF USING ALTERNATIVE MEDIA IN DEVELOPING ENVIRONMENTAL CITIZENSHIP FOR A GROUP OF YOUTH.
}

Shalaby. Sh. ${ }^{(1)}$; Mekaway, H. E. ${ }^{(2)}$ and Imam, Heba, A. A. ${ }^{(3)}$

1) Faculty of Education, Ain Shams University 2) Faculty of Media, Cairo University 3) Al-Ahram Journal

\begin{abstract}
This research purpose is to develop environmental citizenship in a group of youth who are users of the social communication website, namely, the "facebook" measure as one of the media alternative means. Using the quasi-experimental method for the remarkable shortness of traditional media as approved by the pilot study and after reviewing pages and private groups of the environment that exceed (100) groups on the facebook social media in Egypt, researchers have prepared a checklist of the environmental dimensions necessary for developing environmental citizenship in Egypt. The study sample consists of (60) youths divided into three groups, users of facebook, group, page, and the control group.
\end{abstract}

$$
\text { المجلا الثالث والثلاثثو، الجزء الثاني، يونيو } 17 \text { ـ ب r }
$$


The study results showed the effectiveness and impact of alternative media and its means on developing environmental citizenship for youth in Egypt compared to traditional ones and the impact of one of the two means (page) or (group) rather than the other; using as well the Scale of Environmental Citizenship to be applied on page of "Helwa Ya Balady" and group of "Masr Khadra Bina" Which were established on social communication website, namely, facebook as one of alternative media means.

Study results showed that using alternative media models(facebook) has led to development of environmental citizenship for a group of youth, as the first (experimental) group, page of "Helwa Ya Balady" on which the Scale of Environmental Citizenship has been pre/post applied, has shown significant effect and superior performance regarding efficacy of alternative media.

The second experimental group "Masr Khadra Bina" shows significant effect post-application more than the suggested group of the control group which has not been exposed to alternative media; because of the direct interactive impact between the receiver and the sender that makes the message clearer affecting in turn the development of environmental citizenship among youth rather than the traditional media.

The research recommends the necessity of developing specialized environmental pages on facebook through including dimensions of environmental citizenship in more effective way through modern applications. It also recommends seeking assistance of experts in communication technology field to update proposed approaches for presenting environmental dimensions, preparing specialized videos for exposing how to practice positive environmental activities, including as well environmental dimensions through various publications (videos texts) not to be limited only on pages or specialized groups as they are less effective. 